\title{
Enhanced tuberculosis case detection among substitution treatment patients: a randomized controlled trial
}

\author{
Kristi Rüütel ${ }^{1 *}$, Helle-Mai Loit ${ }^{2 \dagger}$, Tiiu Sepp ${ }^{3 \dagger}$, Kai Kliiman ${ }^{4 \dagger}$, Louise-Anne McNutt ${ }^{5+}$ and Anneli Uusküla ${ }^{6+}$
}

\begin{abstract}
Background: Historically, HIV, TB (tuberculosis) and illegal drug treatment services in Estonia have been developed as vertical structures. Related health care services are often provided by different health care institutions and in different locations. This may present obstacles for vulnerable groups, such as injecting drug users (IDU), to access the needed services. We conducted a small scale randomized controlled trial to evaluate a case management intervention aimed at increasing TB screening and treatment entry among IDUs referred from a methadone drug treatment program in Jõhvi, North-Eastern Estonia.
\end{abstract}

Findings: Of the 189 potential subjects, $112(59 \%)$ participated. HIV prevalence was 86\% $(n=96)$ and $7.4 \%(n=8)$ of participants were interferon gamma release assay (IGRA) positive ( $6.5 \%$ were both HIV and IGRA-positive, $n=7$ ). Overall, 44\% of participants $(n=49)$ attended TB clinic, $17(30 \%)$ from control group and $32(57 \%)$ from case management group $(p=0.004)$. None of the participants were diagnosed with TB. In a multivariate model, those randomized to case management group were more likely to access TB screening services.

Conclusions: These findings demonstrate the urgent need for scaling up TB screening among IDUs and the value of more active approach in referring substitution treatment patients to TB services.

Trial registration: ClinicalTrials.gov: NCT01290081

\section{Background}

Illegal drug use has become a risk factor for tuberculosis (TB) as a result of the overlap of epidemiological and social factors associated with both drug use and TB. The spread of HIV infection has further amplified the spread of TB among drug users [1,2]. An increase of tuberculosis among relatively young individuals such as injecting drug users (IDU) who often have active social lives may have serious public health consequences and lead to the spread of tuberculosis infection in the environment. Therefore, HIV infected persons and persons at risk for HIV infection should be closely monitored for $\mathrm{TB}$ even in a country where the prevalence of tuberculosis is low [3].

\footnotetext{
* Correspondence: kristi.ruutel@tai.ee

+ Contributed equally

${ }^{1}$ Department of Infectious Diseases and Drug Abuse Prevention, National Institute for Health Development, Tallinn 11619, Estonia

Full list of author information is available at the end of the article
}

Estonia, located in North-Eastern Europe, is the smallest of the Baltic nations with a total population of approximately 1.3 million people, had the TB incidence rate of 26.2/100,000 in 2008; the proportion of multidrug resistant (MDR) cases (defined as TB caused by $M$. tuberculosis resistant in vitro to isoniazid and rifampicin) among new TB cases was $11.9 \%$ and among relapses $29.5 \%$ respectively. The proportion of TB patients co-infected with HIV was 9.4\% [4,5]. Estonia also has the highest numbers of newly diagnosed HIV cases per 100,000 population in the European Union [6]. The adult injecting drug use prevalence (among 15-44 year old) is estimated to be $2.4 \%$ [7] and HIV-prevalence rates as high as $70 \%$ have been described among IDUs [8]. Previous research has shown that up to $2 \%$ of IDUs have been diagnosed with TB in lifetime. In neighboring country Latvia this percentage is even higher - 7\% [9].

Historically, HIV, TB and illegal drug treatment services in Estonia have been developed as vertical structures. Related health care services are often provided by
C Biomed Central

(C) 2011 Rüütel et al; licensee BioMed Central Ltd. This is an open access article distributed under the terms of the Creative Commons Attribution License (http://creativecommons.org/licenses/by/2.0), which permits unrestricted use, distribution, and reproduction in any medium, provided the original work is properly cited. 
different health care institutions and in different locations. This may present obstacles for vulnerable groups, such as injecting drug users, to access the needed services. Directly observed treatment short course (DOTS) has been implemented in Estonia since 2000 and DOTS plus strategy for MDR-TB treatment has been implemented since August 2001. The DOTS and DOTS plus coverage is $100 \%$. Health care services related to TB diagnostics and treatment are free of charge for all patients [4].

International guidance often supports the idea of onestop shop or integration and co-location of HIV, tuberculosis and drug treatment services. While the fully integrated approach should be viewed as the ideal situation, it may not be attainable immediately due to funding shortfalls or organizational and political constraints. As such, it should be viewed as a goal to be evolved over time [10]. In situations where co-locating services is not possible, other measures can be implemented to increase uptake and coverage of services. Most crucial is efficient collaboration between different service providers. In programs that use additional outreach techniques, such as assistance with transportation, incentives, and food vouchers, very high levels of participation and adherence have been achieved in populations facing the most difficult barriers, such as homelessness, severe mental illness, and active substance abuse [11-13].

The current project sought to test alternative methods in referral of substitution treatment patients to TB control services in order to develop a model of collaboration for TB and drug treatment services.

\section{Methods}

We conducted a small scale randomized controlled trial to evaluate a case management intervention aimed at increasing tuberculosis screening and treatment entry among injecting drug users referred from a methadone drug treatment program in Jõhvi, North-Eastern Estonia.

\section{Setting and sample}

Subjects were recruited from a community-based methadone substitution treatment center in Jõhvi. The center has 250 slots for treatment and operates seven days a week. It is funded by the government and services are free of charge for the patients.

Initial recruitment took place during regular business hours of the treatment center in October 16-18, 2007. All consecutive clients were approached for the study participation.

Recruitment and study randomization was executed by medical nurses who were full-time employers of the substitutions treatment center. They received in-house training regarding standardization of study protocol, procedures to ensure confidentiality, and Mantoux testing. They had been trained also on HIV counseling and testing.

Eligibility criteria included participation in substitution treatment program, age 18 years or more, able to read and write in Estonian or Russian, and able to provide informed consent. In order to link the data from different study sites (substitution treatment center and TB services) each participant was given a unique code.

Consenting participants were referred for TB screening (chest X-ray and additional tests if necessary) to the tuberculosis department of the local county hospital (distance between the two centers is approximately $16 \mathrm{~km})$.

\section{Study instruments and procedures}

1. At the substitution treatment center:

1) Socio-demographic data, TB and IDU history, imprisonment, and TB contacts were collected using a semi-structured questionnaire which was modified from multiple questionnaires [14-17]. The questionnaire was designed for self-administration and required approximately 20 minutes to complete.

2) Whole venous blood was drawn for HIV and interferon- $\gamma$ testing. Pre- and post-test counseling was provided by study nurses. HIV test results were available at the follow-up visit to Mantoux test reading and interferon- $\gamma$ test results after three weeks of initial participation.

3) HIV tests were performed at National HIV Reference Laboratory (using Vironostika HIV Uniform II Ag/Ab; BioMerieux; positive cases were confirmed with INNO LIA HIV I/II Score Westernblot).

4) Interferon- $\gamma$ testing was performed at National Tuberculosis Reference Laboratory using an IGRA assay (QuantiFERON-TB Gold; Cellestis Europe ${ }^{\odot}$ ). The technology is based on the measurement of interferon-gamma (IFN-) secreted from stimulated T-cells previously exposed to Mycobacterium tuberculosis [18]. CDC recommends interferon-gamma release assays (IGRA) in place of TB skin testing in all situations where tuberculin skin testing is recommended as an aid in diagnosing $M$. tuberculosis infection. An IGRA is preferred for testing persons who have received BCG vaccination [19]. In Estonia, BCG vaccination is part of the recommended immunization schedule and is performed to all newborns by the fifth day after birth [20].

5) Mantoux skin testing using 2TU of PPD 23 SSI. Test results were read after 48-72 hours. Induration of $\geq 5 \mathrm{~mm}$ was considered as positive result.

6) Participants who returned to skin test reading were randomly assigned by the study nurses into (1) passive referral group - control group (were 
instructed to schedule an appointment with TB services themselves); or (2) active referral group - case management intervention group (study personnel scheduled the appointment and reminded to keep it, transportation was organized when needed). Participants were expected to attend TB services within the two months after the initial randomization. For those who returned to skin test reading on time an incentive was given (food voucher for local supermarket with the value of 6.4 EUR).

\section{At the tuberculosis department:}

1) Participants who attended TB services were screened for active tuberculosis according to the clinical guidelines of Estonian Respiratory Society [21].

2) Medical doctors filled in a semi-structured questionnaire with the main demographic characteristics, additional tests and procedures done, and the final diagnosis of the participant based on ICD-10.

\section{Statistical analysis}

The interviewers filled questionnaires during the interviews, and checked them immediately after the interview. Completed questionnaires were collected, checked and reviewed for inaccuracies by supervisors on a daily basis. All data was entered twice and the data sets were compared to detect and correct any data entry errors. Statistical analyses were performed with STATA 11.0 (StataCorp LP. College Station, TX). Descriptive statistics were used to characterize participants by intervention group and attendance to TB services. Associations between participant characteristics and attendance to TB services were evaluated by using the Wilcoxon ranksum test or Fisher exact test, followed by univariate and multivariable logistic regressions.

\section{Ethical committee}

The study was approved by the Tallinn Medical Research Ethics Committee and all participants provided oral informed consent.

\section{Results}

\section{Population characteristics}

A total of 189 people were invited to participate in the project. The study included 112 respondents (participation rate $59 \%$ ). The reasons for refusals were recent visit to TB doctor ( $n=34 ; 46 \%)$, no time to participate $(n=22 ; 29 \%)$, did not want to fill in the questionnaire ( $n=17 ; 25 \%)$. Participants and refusals did not differ in mean age, and gender. Timely return rate for skin test reading was 100\% and thus all people initially participating were randomized.
$86 \%$ of participants $(\mathrm{n}=96)$ were HIV-positive and 7.4\% were IGRA-positive $(\mathrm{n}=8)$. Among HIV-positive participants $6.5 \%$ were IGRA-positive $(n=6)$ and among HIV-negative participants - $14.3 \%(\mathrm{n}=2)(\mathrm{p}=$ $0.3)$. Among IGRA-negative participants $13.0 \%(\mathrm{n}=14)$ and among IGRA-positive - $62.5 \%$ were Mantoux-positive $(\mathrm{n}=5)(\mathrm{p}=0.003)$.

None of the participants reported ever having had TB. 35 participants $(31 \%)$ had had chest X-ray done in last year before the study. 27 (24\%) had the last X-ray more than three years before the study and 12 (11\%) did not remember the time of the last X-ray.

Detailed socio-demographic characteristics, TB and drug use history, and test results of the participants in control and case-management groups are presented in Table 1.

\section{Attendance to TB services}

By design, 56 (50\%) were randomized to the intervention and $56(50 \%)$ to the control condition. There were no baseline differences between the intervention and control groups with respect to any socio-demographic or behavioral characteristics, duration of injecting drug use, previous exposure to TB or ever having had TB.

$43.8 \%$ of participants $(49 / 112)$ attended TB clinic, 17 (30.4\%) from control group and 32 (57.1\%) from case management group $(\mathrm{p}=0.004)$. None of them were diagnosed with TB.

We examined the relationships between several potential predictive variables assessed at intake and the outcome measure - attendance to TB services. Potential predictors included age older than 29 years, female gender, more than nine years of education, being employed, injecting drugs less than 10 years, ever been in prison, previous TB contacts, Mantoux and HIV test results, and type of referral (active versus passive). Both in simple and multivariable logistic regression analysis none of the candidate variables was significantly associated to attendance to TB services, except for the type of referral. Thus people from case management group had 3.9 (95\% CI 1.4-10.4) ( $p=0.007)$ times higher odds of attending TB services compared to those from control group.

\section{Cost assessment}

We conducted a cost assessment to quantify the expenditures necessary to implement the active referral program (detailed data are presented in Table 2). We did not include the costs of tests performed at the substitution treatment center (these were performed solely for the research purposes and do not have to be administered routinely in this context) and costs related to TB screening in TB clinic. We used the mean hourly salary for medical nurses in Estonia. Thus for a substitution treatment center to organize one client's TB screening 
Table 1 Socio-demographic characteristics, TB and drug use history, and test results of the participants

\begin{tabular}{|c|c|c|c|}
\hline Characteristic & Total & Control group & Case management group \\
\hline Male participants (\%, 95\% Cl) & $64.9(55.8-73.9)$ & $61.8(48.7-74.9)$ & $67.9(55.4-80.3)$ \\
\hline Mean age in years (SD; range) & $26.2(4.2 ; 19-48)$ & $26.3(3.1 ; 20-33)$ & $26.0(5.2 ; 19-48)$ \\
\hline Sample younger than 30 years of age $(\%, 95 \% \mathrm{Cl})$ & $83.9(77.0-90.8)$ & $82.1(71.9-92.4)$ & $85.7(76.4-95.1)$ \\
\hline \multicolumn{4}{|l|}{ Ethnicity (\%, 95\% Cl) } \\
\hline Estonian & $9.8(4.2-15.4)$ & $8.9(1.3-16.5)$ & $10.7(2.5-19.0)$ \\
\hline Other & $90.2(84.6-96.8)$ & $91.1(83.5-98.7)$ & $89.3(81.0-97.5)$ \\
\hline Persons with less than 12 years of education $(\%, 95 \% \mathrm{Cl})$ & $56.3(46.9-65.6)$ & $51.8(38.4-65.1)$ & $60.7(47.7-73.8)$ \\
\hline Percentage of employed participants (\%, 95\% Cl) & $49.1(39.7-58.5)$ & $48.2(34.9-61.6)$ & $50.0(36.6-63.4)$ \\
\hline $\begin{array}{l}\text { Percentage of participants who had been in prison at least once in } \\
\text { lifetime }(\%, 95 \% \mathrm{Cl})\end{array}$ & $61.6(52.5-70.6)$ & $67.9(55.4-80.3)$ & $55.4(42.1-68.6)$ \\
\hline Mean age at initiation of IDU (SD; range) & $16.8(3.3 ; 11-30)$ & $17.3(3.6 ; 11-26)$ & $16.2(3.0 ; 11-30)$ \\
\hline Mean duration of IDU in years (SD; range) & $9.4(3.6 ; 2-24)$ & $9.0(3.4 ; 2-20)$ & $9.8(3.8 ; 4-24)$ \\
\hline Percentage uninsured by the national health insurance $(\%, 95 \% \mathrm{Cl})$ & $36.6(27.5-45.7)$ & $35.7(22.9-48.5)$ & $37.5(24.6-50.4)$ \\
\hline Percentage of people with TB contacts $(\%, 95 \% \mathrm{Cl})$ & $24.1(16.1-32.2)$ & $66.7(53.4-79.9)$ & $81.1(70.4-91.9)$ \\
\hline Percentage of people who had had TB (\%, 95\% Cl) & 0.0 & 0.0 & 0.0 \\
\hline Percentage HIV-antibody positive & $86.2(79.7-92.8)$ & $88.7(80.0-97.4)$ & $83.9(74.1-93.7)$ \\
\hline Percentage IGRA-positive (\%, 95\% Cl) & $7.4(2.4-12.4)$ & $9.4(1.4-17.5)$ & $5.5(0.0-11.6)$ \\
\hline Percentage Mantoux-positive ( $\geq 5 \mathrm{~mm})(\%, 95 \% \mathrm{Cl})$ & $17.0(9.9-24.0)$ & $19.6(9.0-30.3)$ & $14.3(4.9-23.6)$ \\
\hline
\end{tabular}

would cost an additional 18 EUR and for 200 clients 3,600 EUR.

\section{Discussion}

Drug users constitute a high-risk group for whom screening, prevention of infection, diagnosis, and treatment of TB may pose particular challenges. The development of TB services capable of engaging drug users (those both in and out of drug treatment programs) has potential for disrupting a significant chain of rapid TB transmission [1]. Drug treatment programs can provide a strategic setting for screening and directly observed preventive therapy, and for referring IDUs to needed health care, especially for TB and antiretroviral therapies [22,23].

None of our participants reported ever having had tuberculosis. At the same time $6.5 \%$ of all participants were positive for both HIV-antibodies and IGRA (as a marker of latent TB). These people constitute an especially high risk group for developing active tuberculosis. The risk of developing active TB could be as high as $5-10 \%$ per year [24].
Despite the fact that substitution treatment patients attend the clinic daily and many of them who are $\mathrm{HIV}$-infected also attend infectious diseases clinics, only one third of them had had a chest X-ray performed within last 12 months prior to the recruitment. These results show the need to implement more active TB screening among methadone substitution treatment patients.

Results of our pilot program show that the uptake of TB screening services can be increased with more active referral, help in transportation and incentives. Other studies have also shown that monetary incentives can increase participation in programs (for example the return rate for TB skin test reading) [25].

Participants were very favorably inclined toward the pilot program and the high acceptance rate of the initial screening in substitution treatment center suggests that this type of approach can be incorporated into daily activities of substitution treatment program. Study staff did not meet any major obstacles and problems related to recruitment of participants, administration of the questionnaire and referrals.

Table 2 Costs related to referral of one patient

\begin{tabular}{|c|c|c|c|c|}
\hline Task group & Resources used & Cost per unit & $\begin{array}{c}\text { Units per } \\
\text { patient }\end{array}$ & $\begin{array}{c}\text { Price per } \\
\text { patient }\end{array}$ \\
\hline $\begin{array}{l}\text { Counseling and } \\
\text { referral }\end{array}$ & Nursing staff time & 6.4 EUR per hour (including all taxes) & 0.5 hour & 3.2 EUR \\
\hline Transportation & $\begin{array}{l}\text { Substitution treatment center's } \\
\text { vehicle }\end{array}$ & $\begin{array}{c}2 \mathrm{~L} \text { of gas }+1 \text { hour of driving staff time }=2 \text { EUR }+ \\
6.4 \text { EUR }\end{array}$ & 1 & 8.4 EUR \\
\hline Incentives & Food voucher & 6.4 EUR per voucher & 1 voucher & 6.4 EUR \\
\hline Total & & & & 18 EUR \\
\hline
\end{tabular}


Cost assessment showed that with relatively small additional investments the uptake of TB screening for IDUs can be considerably increased. In comparision the mean cost of non-MDR-TB treatment case in Estonia is 3,251 EUR and of the MDR-TB patient - 8,469 EUR [26]. Early detection of TB improves the treatment outcomes [27] and reduces the period of infectiousness thus investment in TB screening for IDUs can be cost saving.

\section{Limitations}

Small sample size, recruitment in only one centre, and sampling in methadone treatment program would not have accessed important groups of active injecting drug users, and therefore the results cannot be generalized to the whole IDU population. Generalisability might be further affected by the modest response rate among methadone center clients. Further, given that the HIV prevalence among methadone center clients was very high additional research is needed in terms on need and methods for screening among IDUs not in contact with harm reduction services. However, the main reason for declining study participation was recent contact with TB services and thus our intervention reached those in most need for TB screening.

\section{Conclusions}

This pilot study illustrates the urgent need for scaling up TB screening among IDUs and the value of more active approach in referring substitution treatment patients to TB services.

\section{List of abbreviations used}

CDC: Centers for Disease Control and Prevention; DOTS: directly observed treatment short course; EUR: euro; IDU: injecting drug user; IGRA: interferon gamma release assay; MDR: multi-drug resistant; TB: tuberculosis

\footnotetext{
Acknowledgements and Funding

We gratefully acknowledge the help of our study nurses Nadežda and Ljubov for their excellent work, of Dr Veronika Iljina for organizing services in TB department, of Dr Ljudmilla Priimägi for her help in adapting the Russian version of the questionnaire, and of Heti Pisarev for help in data analysis. This study was funded by the National Institute for Health Development, Estonia, from European Commission funded project Expanding Network for Comprehensive and Coordinated Action on HIV/AIDS prevention among IDUs and Bridging Population Nr 2005305 (ENCAP), National HIV/AIDS Strategy for 2006-2015, National Tuberculosis Control Program for 2003-2007, grant No SF0180060s09 from the Estonian Ministry of Education and Research, and the New York State International Training and Research Program grant 2D43TW000233, from the National Institutes of Health/ Fogarty International Center and the National Institute on Drug Abuse (NIDA).

\section{Author details}

${ }^{1}$ Department of Infectious Diseases and Drug Abuse Prevention, National Institute for Health Development, Tallinn 11619, Estonia. ${ }^{2}$ Department of Chronic Diseases, National Institute for Health Development, Tallinn 11619, Estonia. ${ }^{3}$ LLC Corrigo, Jõhvi 41532, Estonia. ${ }^{4}$ Lung Clinic, Tartu University Hospital, Tartu 51014, Estonia. ${ }^{5}$ School of Public Health, University at Albany,
}

State University of New York, Rensselaer, NY 12144, USA. ${ }^{6}$ Department of Public Health, University of Tartu, Tartu 50411, Estonia.

\section{Authors' contributions}

$\mathrm{KR}, \mathrm{AU}, \mathrm{HML}$ and $\mathrm{KK}$ designed the study. KR and TS supervised the data collection. KR, AU and LAM designed the data analysis and structure of the manuscript. KR conducted the statistical analysis. KR wrote the first draft of the manuscript. All of the authors contributed to the final version of the manuscript. All of the authors read and approved the final manuscript.

\section{Competing interests}

The full content of this paper has not been published elsewhere, nor is it being considered elsewhere, nor are there any conflicts of interest contained therein. Preliminary findings from this study have been presented at the XVII International AIDS Conference (Mexico City, Mexico, August 3-8, 2008). Abstract titled: Pilot program for tuberculosis control among methadone substitution treatment patients in Estonia (Rüütel K, Uusküla A, Loit HM).

Received: 1 March 2011 Accepted: 15 June 2011

Published: 15 June 2011

\section{References}

1. Perlman DC, Salomon N, Perkins MP, Yancovitz S, Paone D, Des Jarlais DC: Tuberculosis in drug users. Clin Infect Dis 1995, 21:1253-1264.

2. Friedland G: Infectious disease comorbidities adversely affecting substance users with HIV: hepatitis C and tuberculosis. J Acquir Immune Defic Syndr 2010, 55:S37-S42.

3. Van Deutekom H, Warris-Versteegent AA, Krijnen P, Posternat CA, van Wijngaardent JK, van den Hock JAR, Coutinho RA: The HIV epidemic and its effect on the tuberculosis situation in the Netherlands. Tuberc Lung Dis 1993, 74:159-162.

4. Estonian National Tuberculosis Registry. [http://www.tai.ee/?id=2535].

5. Estonian Statistical Database. [http://www.stat.ee/rahvastik].

6. European Centre for Disease Prevention and Control/WHO Regional Office for Europe: HIV/AIDS surveillance in Europe 2007 Stockholm; European Centre for Disease Prevention and Control.

7. Uusküla A, Rajaleid K, Talu A, Abel K, Rüütel K, Hay G: Estimating injection drug use prevalence using state wide administrative data sources: Estonia, 2004. Addict Res Theory 2007, 15:411-424.

8. Lõhmus L, Rüütel K, Abel-Ollo K, Loit HM, Talu A, Uusküla A: HIV-nakkuse ning teiste infektsioonide ja riskikäitumise levimus süstivate narkomaanide seas Tallinnas ja Kohtla-Järvel, 2007 Tallinn, Estonia; 2008, HIV and other infections and related risk behaviours among injecting drug users, 2007.

9. Rüütel K, Karnite A, Brokere I, Talu A, Abel-Ollo K, Kirvelaite G, Uusküla A: Prevalence of latent tuberculosis and risk factors among injecting drug users in Estonia and Latvia. 5th European Conference on Clinical and Social Research on AIDS and Drugs: 28-30 April 2009; Vilnius

10. Sylla L, Bruce RD, Kamarulzaman A, Altice FL: Integration and co-location of HIV/AIDS, tuberculosis and drug treatment services. Int J Drug Policy 2007, 18:306-312.

11. El Sadr W, Medard F, Barthaud V: Directly observed therapy for tuberculosis: the Harlem Hospital experience, 1993. Am J Public Health 1996, 86:1146-1149.

12. Friedmann PD, D'Aunno TA, Jin L, Alexander JA: Medical and psychosocial services in drug abuse treatment: do stronger linkages promote client utilization? Health Services Res 2000, 35:443-465.

13. Strathdee SA, Ricketts EP, Huettner S, Cornelius L, Bishai D, Havens JR, Beilenson P, Rapp C, Lloyd JL, Latkin CA: Facilitating entry into drug treatment among injection drug users referred from a needle exchange program: Results from a community-based behavioral intervention trial. Drug Alcohol Depend 2000, 83:225-232.

14. Des Jarlais DC, Perlis TE, Stimson GV, Poznyak V, WHO Phase II Drug Injection Collaborative Study Group: Using standardized methods for research on HIV and injecting drug use in developing/transitional countries: case study from the WHO Drug Injection Study Phase II. BMC Public Health 2006, 6:54.

15. Salomon N, Perlman DC, Freidmann P, Perkins MP, Ziluck V, Des Jarlais DC, Paone D: Knowledge of tuberculosis among drug users relationship to return rates for tuberculosis screening at a syringe exchange. J Subst Abuse Treat 1999, 3:229-235. 
16. UNAIDS/WHO Working Group on Global HIV/AIDS and STI Surveillance: Guidelines for second generation HIV surveillance: The next decade World Health Organization and Joint United Nations Programme on HIV/AIDS; 2000.

17. Wolfe H, Marmor M, Maslansky R, Nichols S, Simberkoff M, Des Jarlais DC, Moss A: Tuberculosis knowledge among New York City injection drug users. Am J Public Health 1995, 85:985-988.

18. Cellestis: QuantiFERON-TB Gold In-Tube assay. Test principle.[http:// www.cellestis.com/RM/Content/aust/qtfproducts_tbgoldintube_faqs.html].

19. Centers for Diseases Control and Prevention: Updated guidelines for using interferon gamma release assays to detect Mycobacterium tuberculosis infection - United States, 2010. MMWR 2010, 59:1-25.

20. Estonian Health Board: Vaktsineerimine [Vaccinations]:[http://www. terviseamet.ee/nakkushaigused/vaktsineerimine.html].

21. Vink K: Tuberkuloosi diagnostika, ravi ja ravi jälgimise juhised Tartu, Estonia; 2004 [http://www.tai.ee/failid/TB_ravijuhis.pdf], Guidelines for diagnosis, treatment and follow-up of tuberculosis.

22. Durante AJ, Selwyn PA, O'Connor PG: Risk factors for and knowledge of Mycobacterium tuberculosis infection among drug users in substance abuse treatment. Addiction 1998, 93:1393-1401.

23. Estrada AL: Epidemiology of HIV/AIDS, hepatitis B, hepatitis C, and tuberculosis among minority injection drug users. Public Health Rep 2002, 117:S126-S134

24. Selwyn PA, Hartel D, Lewis VA, Schoenbaum EE, Vermund SH, Klein RS, Walker AT, Friedland GH: A prospective study of the risk of tuberculosis among intravenous drug users with human immunodeticiency virus infection. New Engl J Med 1989, 320:545-550.

25. Malotte CK, Rhodes F, Mais KE: Tuberculosis screening and compliance with return for skin test reading among active drug users. Am J Public Health 1998, 88:792-796.

26. Kliiman K, Centis R, Migliori GB, Floyd K, Hollo V, Danilovits M, Vink K, Nathanson E: Evaluation of DOTS-Plus in Estonia. Int J Tuberc Lung Dis 2005, 11:133s.

27. Kliiman K, Altraja A: Predictors of poor treatment outcome in multi- and extensively drug-resistant pulmonary TB. Eur Respir J 2009, 33:1085-1094.

doi:10.1186/1756-0500-4-192

Cite this article as: Rüütel et al:: Enhanced tuberculosis case detection among substitution treatment patients: a randomized controlled trial. BMC Research Notes 2011 4:192.

\section{Submit your next manuscript to BioMed Central and take full advantage of:}

- Convenient online submission

- Thorough peer review

- No space constraints or color figure charges

- Immediate publication on acceptance

- Inclusion in PubMed, CAS, Scopus and Google Scholar

- Research which is freely available for redistribution

Submit your manuscript at www.biomedcentral.com/submit
Biomed Central 